International Journal of Advanced Technology in Mechanical, Mechatronics and Materials
(IJATEC)
Vol. 02, No. 2 (2021) 70-75
Institute for Research on Innovation and Industrial System (IRIS)

\title{
The Development of Fine Surface Roughness of FeCrAl Substrate by Gamma Alumina Coating Material Through Nickel Oxide Catalyst
}

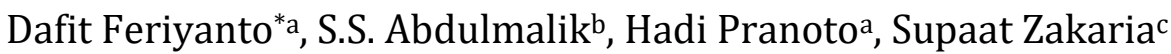 \\ a Department of Mechanical Engineering, Faculty of Engineering, Universitas Mercu Buana, Jakarta, Indonesia \\ ${ }^{b}$ Department of Mechanical Engineering, Faculty of Engineering and Technology, Nigerian Army University, \\ Borno State, Nigeria \\ cDepartment of Mechanical Engineering, Politeknik Ungku Omar, Perak, Malaysia
}

\begin{abstract}
The most commonly used method for protecting atmospherically exposed steel against corrosion, is the application of protective organic coating systems. It is widely recognized that the stability of the coating-substrate interface is related to the interfacial adhesion forces and electrochemical properties of this region. This study aims to develop fine surface roughness by ultrasonic and electroplating coating methods that applied for FeCrAl catalytic converter. This method consists of thwo methods which are ultrasonic bath that carried out by frequency of $35 \mathrm{kHz}$ and various ultrasonic times of 1, 1.5, 2, 2.5 and 3 hours is imposed, and the electroplating was conducted for several variation times of $15,30,45,60$ and 75 minutes, current density of $8 \mathrm{~A} / \mathrm{dm}^{2}$. The result shows that the surface roughness of UB samples in between 0.11 to $0.21 \mu \mathrm{m}$, UBdEL samples of 0.81 to $2.17 \mu \mathrm{m}$, UB+EL samples of 0.64 to $1.63 \mu \mathrm{m}$ and EL samples of 0.69 to $1.11 \mu \mathrm{m}$. The finest surface of each technique are located at UB $1.5 \mathrm{~h}$, UBdEL 45 minutes, UB $1.5 \mathrm{~h}+\mathrm{EL} 30$ minutes and UB 30 minutes. That data is supported by coating thickness of coated FeCrAl substrate where UB samples in between $2-2.8 \mu \mathrm{m}$, UBdEL samples of 4.1 to $5 \mu \mathrm{m}$, UB+EL samples of 9.1 to 12 $\mu \mathrm{m}$ and EL samples of 6.2 to $11.3 \mu \mathrm{m}$.
\end{abstract}

Keywords: surface roughness; electroplating; ultrasonic; catalytic converter

DOI: $10.37869 /$ ijatec.v2i2.46

Received 1 July 2021; Accepted 1 September 2021; Available online 18 November 2021

(C) The Authors. Published by IRIS. This is an open access article under the CC BY-NC-SA license cc) (1) (2)

\section{Introduction}

A washcoat is a catalysts carrier with high surface area. This material is usually an oxide layer such as $\mathrm{Al}_{2} \mathrm{O}_{3}, \mathrm{SiO}_{2}, \mathrm{TiO}_{2}$, or $\mathrm{SiO}_{2}-\mathrm{Al}_{2} \mathrm{O}_{3}$ [1]. In this research, washcoat material is a thin layer of GammaAlumina $\left(\gamma-\mathrm{Al}_{2} \mathrm{O}_{3}\right)$ coating, typically $20-150 \mu \mathrm{m}$ of thickness with a high surface area on the top of substrate. It also called as a catalyst carrier and acts as an intermediate layer in order to oxidation and reduction processes occur [2].

Currently, the metallic CATCO was interesting component to explore as compared to ceramic material. Therefore, this study has chosen FeCrAl metallic substrate as a main CATCO component. The FeCrAl is generally considered as metallic substrates due to their advantage in the high thermal stability, high corrosion resistance, including the strong adherence of oxide film on the surface of substrate when applied the appropriate surface treatment [3].

The conventional technique for adhering $\mathrm{NiO}$ catalyst on substrate is by wash coating techniques that generally comprise of preparing a coating formed from a high surface area oxide blended with one or more catalysts and dipping the monolith structure into that coating blend [4-6]. One of the most common methods to form a thin layer of oxide coatings on the metallic substrate is dip coatings, 
which combined with some pre-treatments, such as growing a number of textured alumina whiskers on the surface of the metal support and shortened the diffusion path before depositing the washcoat [7]. There are some problems that observed which are Rough surface roughness of FeCrAl catalytic converter has been observed as a main problem that need to solve due to it effect on exhaust gas conversion that performed by Catalytic converter. The exploration of FeCrAl metallic material and Gamma alumina as coating material not fully explored in catalytic converter Application [8-9]. Therefor the main objective of this research was to investigate an appropriate parameter of coating process in order to achieve fine surface roughness of FeCrAl substrate. To Analyze the effect of surface roughness in exhaust gas conversion on gasoline engine.

\section{Research Methodology}

Ultrasonic bath is conducted to $\mathrm{FeCrAl}$ foil which cut in size of $40 \mathrm{~mm}$ x $20 \mathrm{~mm}$ and $\gamma-\mathrm{Al}_{2} \mathrm{O}_{3}$ powder. The samples are cleaned in water and then proceed in ethanol for 5 minutes. During ultrasonic process, the frequency of $35 \mathrm{kHz}$ and various ultrasonic times of 1, 1.5, 2, 2.5 and 3 hours is imposed. The samples is immersed into the beaker with $\gamma-\mathrm{Al}_{2} \mathrm{O}_{3}$ powder for $3 \mathrm{~g}$ in each samples and ethanol with the concentration of $20 \mathrm{~g} / \mathrm{l}$. The other methods will be conducted i.e. ultrasonic bath during electroplating. It principle of the process is similar with electroplating process with sulphamate type as electrolyte, but the differences is the stirrer is replaced by ultrasonic sources. It conducted in order to achieve homogenizing of coating process or levelling the spread coating material. Those process is conducted by referring Sebayang et al., (2012) [2]. Figure 1 shows the mechanism of ultrasonic bath and ultrasonic bath during electroplating process.

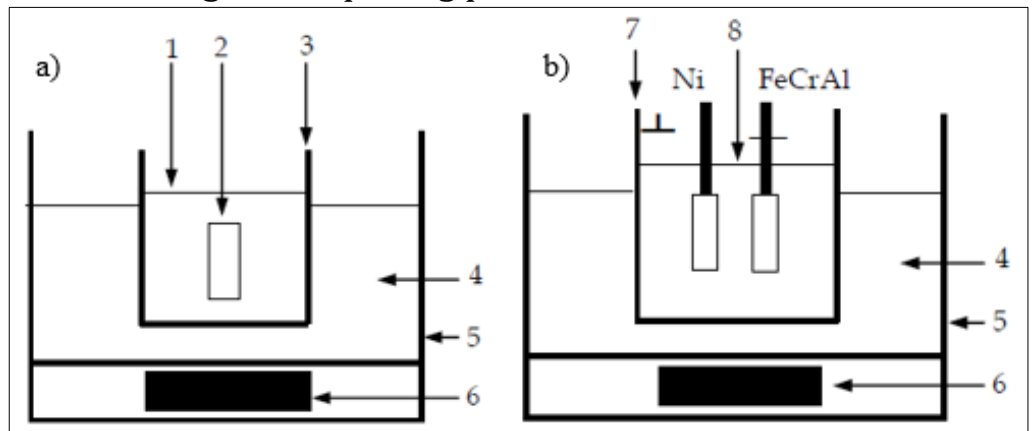

Figure 1. Schematic diagram of a) ultrasonic cleaning bath and b) ultrasonic bath during electroplating:(1) Ethanol; (2) Specimen; (3) Beaker; (4) Water; (5) Bath; (6) Ultrasonic source; (7) Plating tank and (8) Electrolyte solution

According to Sebayang et al., (2012) [2] that the electroplating psrocess was conducted using some equipments such as laboratory power supply, retorch clamp, hot plate, magnetic steering, glass beaker, petri disc, and, etc. Main purpose of the nickel electroplating process is for depositing nickel onto $\mathrm{FeCrAl}$ and embed the $\gamma-\mathrm{Al}_{2} \mathrm{O}_{3}$ into $\mathrm{FeCrAl}$ substrate. Electroplating process is conducted through some components such as electrolyte, anti-pitting agent, anode and cathode. Sulphamate type is used as the electrolyte medium. It based on Ade (2012) which has been used the sulphamate types as electrolyte which consists of consisted of nickel sulphamate $\left(\mathrm{Ni}\left(\mathrm{SO}_{3} \mathrm{NH}_{2}\right)_{2} 4 \mathrm{H}_{2} \mathrm{O}\right)$, nickel chloride $\left(\mathrm{NiCl} 6 \mathrm{H}_{2} \mathrm{O}\right)$, boric acid $\left(\mathrm{H}_{2} \mathrm{BO}_{3}\right)$ and sodium lauryal sulphate $\left(\mathrm{C}_{12} \mathrm{H}_{25} \mathrm{SO}_{4} \mathrm{Na}\right)$ and it resulted that electrolyte can be optimize the electroplating process. Therefore, in this research will be generated using sulphamate types which consists of nickel (II) sulphate 6-hydrate $\left(\mathrm{NiSO}_{4} \cdot 6 \mathrm{H}_{2} \mathrm{O}\right)$, nickel (ii) chloride $\left(\mathrm{NiCl}_{2} \cdot 6 \mathrm{H}_{2} \mathrm{O}\right)$, boric acid $\left(\mathrm{H}_{3} \mathrm{BO}_{3}\right)$, and sodium dodecyl sulfate $\left(\underline{\mathrm{C}}_{12} \underline{\mathrm{H}}_{25} \underline{\mathrm{OSO}}_{3} . \mathrm{Na}\right)$ with the composition is shown in Table 1 . The electrolyte prepared with distilled water, at a constant temperature of $40-60{ }^{\circ} \mathrm{C}$, and $\mathrm{pH}$ value of solution adjusted to $2.5-5 \mathrm{using} \mathrm{HCl}$ and $\mathrm{NaOH}$ reagent. The electrolyte agitated using a magnetic stirrer. A nickel plate substrate acted as anode with the size of $50 \mathrm{~mm} \times 10 \mathrm{~mm}$, whereas a FeCrAl acted as cathode with the size of $40 \mathrm{~mm} \times 20 \mathrm{~mm}$. The distance between anode and cathode is set at $25 \mathrm{~mm}$. The electroplating was conducted for several variation times of 15, 30, 45, 60 and 75 minutes, current density of $8 \mathrm{~A} / \mathrm{dm}^{2}, 3 \mathrm{~g} \gamma-\mathrm{Al}_{2} \mathrm{O}_{3}$ inserted into the beaker for each sample and total surface area of $1600 \mathrm{~mm}^{2}$ in two sides. The schematic diagram of electroplating process is shown in Figure 2. 
Table 1. Chemical composition of electrolyte

\begin{tabular}{lc}
\hline \multicolumn{1}{c}{ Electrolyte solution } & Composition (\%) \\
\hline $\mathrm{NiSO}_{4} 6 \mathrm{H}_{2} \mathrm{O}$ & 51.25 \\
$\mathrm{NiCl}_{6} \mathrm{H}_{2} \mathrm{O}$ & 0.85 \\
$\mathrm{H}_{2} \mathrm{BO}_{3}$ & 5.12 \\
$\mathrm{C}_{12} \mathrm{H}_{25} \mathrm{SO}_{4} \mathrm{Na}$ & 42.73 \\
\hline
\end{tabular}

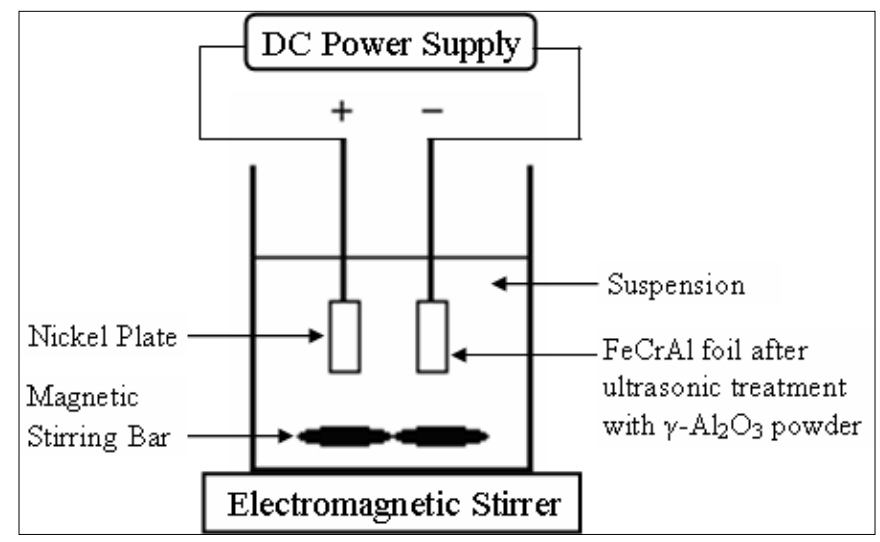

Figure 2. Schematic diagram of electroplating process

There is correlation of the surface roughness in CATCO regarding to the toxic emission flow through the CATCO. Surface roughness is can effect to the chemical reaction (Zhao et al., 2001) which automatically effect to the result of exhaust emission of the CATCO. In this research will investigate which effective between low or high surface roughness in field of reducing emission. Surface roughness machine (Mitutoyu SJ-400) is arranged by $\lambda_{c}$ of $0.8 \mathrm{~mm}, \lambda_{c}$ of $2.5 \mu \mathrm{m}$, eva-L of $4 \mathrm{~mm}$ and Roughness range of 800 .

\section{Results and Discussions}

\subsection{Surface Roughness Analysis}

Surface roughness analysis were performed to coated and uncoated FeCrAl substrate by $\gamma-\mathrm{Al}_{2} \mathrm{O}_{3}$. From the surface roughness machine can be observed surface roughness (Ra) of material and surface roughness mean squared (Rq). Ra of raw material and coated material (UB, UBdEL, UB+EL and EL samples) are listed in Table 2. Surface roughness analysis is measure for 3 times in order to investigate real surface roughness of coated and uncoated material. Ra of raw material show in constant value for $0.02 \mu \mathrm{m}$ while for coated material show in fluctuation value. The lowest number of Ra value for UB, UBdEL, UB+EL and EL samples are $0.11 \mu \mathrm{m}, 0.81 \mu \mathrm{m}, 0.64 \mu \mathrm{m}$ and $0.69 \mu \mathrm{m}$ which located at UB $1.5 \mathrm{~h}$, UBdEL $45 \mathrm{~min}, \mathrm{UB}+\mathrm{EL} 30 \mathrm{~min}$ and EL $30 \mathrm{~min}$, respectively. Highest Ra value is located at UB $3 \mathrm{~h}$, UBdEL $75 \mathrm{~min}, \mathrm{UB}+\mathrm{EL} 75 \mathrm{~min}$ and EL $15 \mathrm{~min}$ for $0.21 \mu \mathrm{m}, 2.17 \mu \mathrm{m}, 1.63 \mu \mathrm{m}$ and $1.11 \mu \mathrm{m}$, respectively. Different treatment has shown he different optimum treatment time such as for UB is $1.5 \mathrm{~h}$, UBdEL is $45 \mathrm{~min}, \mathrm{UB}+\mathrm{EL}$ is $30 \mathrm{~min}$ and $\mathrm{El}$ is $30 \mathrm{~min}$. It may caused by $\gamma-\mathrm{Al}_{2} \mathrm{O}_{3}$ powder as coating material show decreasing particle size up to optimum time for each treatment and continued by small agglomeration phenomena which lead to Ra increment. It supported by previous researcher [10] that higher ultrasonic process will produce smaller surface roughness of material. However, there is certain limit ultrasonic time which caused the agglomeration of washcoat material. Therefore, in ultrasonic time of 45 minutes and above shown the rougher surface roughness. It also may caused by the washcoat material leading to reach the deformation plastic area (Feriyanto et al., 2017a). Level of surface roughness of coated and uncoated material from fine to rough surface is raw material, UB samples, UB+EL samples, EL samples and UBdEL samples. In UB samples, $\gamma-\mathrm{Al}_{2} \mathrm{O}_{3}$ powder is not fully embedded by high cavitations bubbles which led to small amount of washcoat material into $\mathrm{FeCrAl}$ substrate. In UB+EL samples shown the potential coating technique to produce fine surface roughness in $\mathrm{FeCrAl}$ substrate through combination of ultrasonic and electroplating methods due to beside washcoating, ultrasonic also purposed to cleaning FeCrAl substrate from other chemical [11]. Therefore, the washcoat material more intents to embedded into FeCrAl substrate. 
Table 2. Surface roughness of coated and uncoated FeCrAl substrate

\begin{tabular}{|l|c|c|c|c|}
\hline \multicolumn{1}{|c|}{ Sample designation } & $\begin{array}{c}\text { Ra Test 1 } \\
(\mu \mathrm{m})\end{array}$ & $\begin{array}{c}\text { Ra Test 2 } \\
(\mu \mathrm{m})\end{array}$ & $\begin{array}{c}\text { Ra Test 3 } \\
(\mu \mathrm{m})\end{array}$ & $\begin{array}{c}\text { Average } \\
(\mu \mathrm{m})\end{array}$ \\
\hline Raw & 0.02 & 0.02 & 0.02 & 0.02 \\
\hline UB 1 h & 0.14 & 0.13 & 0.15 & 0.14 \\
\hline UB 1.5 h & 0.1 & 0.12 & 0.1 & 0.11 \\
\hline UB 2 h & 0.13 & 0.13 & 0.12 & 0.13 \\
\hline UB 2.5 h & 0.13 & 0.12 & 0.14 & 0.13 \\
\hline UB 3 h & 0.27 & 0.17 & 0.19 & 0.21 \\
\hline UBdEL 15 min & 1.41 & 2.35 & 1.08 & 1.61 \\
\hline UBdEL 30 min & 1.07 & 1.22 & 1.56 & 1.28 \\
\hline UBdEL 45 min & 1.05 & 1.04 & 0.34 & 0.81 \\
\hline UBdEL 60 min & 1.73 & 1.59 & 2.21 & 1.84 \\
\hline UBdEL 75 min & 1.65 & 3.01 & 1.85 & 2.17 \\
\hline UB 1h+EL 15 min & 0.87 & 1.13 & 1.18 & 1.06 \\
\hline UB 1.5h+EL 30 min & 0.97 & 0.6 & 0.35 & 0.64 \\
\hline UB 2h+EL 45 min & 0.97 & 0.88 & 0.74 & 0.86 \\
\hline UB 2.5h+EL 60 min & 1.56 & 1.73 & 0.86 & 1.38 \\
\hline UB 3h+EL 75 min & 2.7 & 1.56 & 0.62 & 1.63 \\
\hline EL 15 min & 1.27 & 1.04 & 1.03 & 1.11 \\
\hline EL 30 min & 0.8 & 0.7 & 0.56 & 0.69 \\
\hline EL 45 min & 0.85 & 0.92 & 1 & 0.92 \\
\hline EL 60 min & 1.25 & 1.05 & 0.9 & 1.07 \\
\hline EL 75 min & 0.79 & 1.06 & 1.27 & 1.04 \\
\hline
\end{tabular}

Ra increment of treated samples shown a significant difference between lowest Ra and highest Ra. For UB shows the increment of $47.62 \%$, UBdEL of $62.67 \%$, UB+EL of $60.74 \%$ and EL of $37.84 \%$. From these results shows that ultrasonic technique give a significant effect to the coating layer and it caused by agglomeration and decrement $\gamma-\mathrm{Al}_{2} \mathrm{O}_{3}$ powder as compared to electroplating technique. Low current density and low voltage that performed in electroplating technique my cause insignificant effect to the Ra of coated material.

\subsection{Surface Roughness Mean Square Analysis}

In surface roughness machine also shows $\mathrm{Rq}$ value of coated and uncoated material which is shown in Table 3. Rq value is reflected from the Ra value. Therefore, when $\mathrm{Ra}$ is increased, $\mathrm{Rq}$ is increased as well. $\mathrm{Ra}$ and $\mathrm{Rq}$ is quite related to the CATCO product and its effectiveness on the exhaust emission reaction. That correlation regarding to the toxic emission flow through the CATCO where it can affect to the chemical reaction of exhaust emission of the CATCO. When surface roughness is low, it will extend the reaction time of exhaust emission which led to preferable on conversion process to the green emission of $\mathrm{CO}_{2}$ and $\mathrm{H}_{2} \mathrm{O}$ forms [12].

The lowest $\mathrm{Rq}$ for each treatment where the lowest $\mathrm{Rq}$ is shown by UB $1.5 \mathrm{~h}$ followed by EL $30 \mathrm{~min}$, UB+EL $30 \mathrm{~min}$ and UBdEl $45 \mathrm{~min}$ with the value of $0.49 \mu \mathrm{m}, 3.02 \mu \mathrm{m}, 3.7 \mu \mathrm{m}$ and $4.9 \mu \mathrm{m}$, respectively. Fluctuation $\mathrm{Rq}$ is observed for coating material. It may caused by not uniformity of wall thickness of FeCrAl surface. It may influence to the non-uniformity temperature distribution and protection when it applied in high temperature of $1000-1400^{\circ} \mathrm{C}$. That phenomenon may affect to the thermal stability and conversion efficiency of FeCrAl substrate in converting pollutant which is $\mathrm{HC}, \mathrm{NO}_{x}$ and $\mathrm{CO}$ to the $\mathrm{H}_{2} \mathrm{O}$ and $\mathrm{CO}_{2}[13,14]$.

Table 3. Surface roughness mean squared of coated and uncoated FeCrAl substrate

\begin{tabular}{lcccc}
\hline \multicolumn{1}{c}{ Sample name } & $\begin{array}{c}\text { Rq Test 1 } \\
(\mu \mathrm{m})\end{array}$ & $\begin{array}{c}\text { Rq Test 2 } \\
(\mu \mathrm{m})\end{array}$ & $\begin{array}{c}\text { Rq Test 3 } \\
(\mu \mathrm{m})\end{array}$ & $\begin{array}{c}\text { Average } \\
(\mu \mathrm{m})\end{array}$ \\
\hline Raw & 0.03 & 0.03 & 0.03 & 0.03 \\
UB 1 h & 0.24 & 0.1 & 0.23 & 0.57 \\
UB 1.5 h & 0.14 & 0.16 & 0.19 & 0.49 \\
UB 2 h & 0.24 & 0.16 & 0.22 & 0.62 \\
UB 2.5 h & 0.27 & 0.14 & 0.22 & 0.63
\end{tabular}




\begin{tabular}{lcccc} 
UB 3 h & 0.15 & 0.16 & 0.41 & 0.72 \\
UBdEL 15 min & 1.82 & 4.38 & 1.47 & 7.67 \\
UBdEL 30 min & 1.41 & 1.57 & 2.57 & 5.55 \\
UBdEL 45 min & 1.6 & 2.87 & 0.43 & 4.90 \\
UBdEL 60 min & 2.38 & 2.05 & 2.9 & 7.33 \\
UBdEL 75 min & 1.07 & 5.64 & 5.92 & 12.63 \\
UB 1h+EL 15 min & 1.32 & 1.45 & 1.5 & 4.27 \\
UB 1.5h+EL 30 min & 1.6 & 1.29 & 0.81 & 3.70 \\
UB 2h+EL 45 min & 1.47 & 1.79 & 1.82 & 5.08 \\
UB 2.5h+EL 60 min & 2.16 & 2.56 & 1.09 & 5.81 \\
UB 3h+EL 75 min & 3.46 & 2.15 & 1.94 & 7.55 \\
EL 15 min & 1.71 & 1.46 & 1.41 & 5.11 \\
EL 30 min & 1.36 & 0.94 & 0.72 & 3.02 \\
EL 45 min & 1.08 & 1.25 & 1.29 & 3.62 \\
EL 60 min & 1.98 & 1.42 & 1.71 & 4.34 \\
EL 75 min & 1.01 & 1.46 & 1.87 & 4.58 \\
\hline
\end{tabular}

\section{Conclusions}

Surface roughness and coating thickness were investigated by Surface roughness machine (Mitutoyu SJ-400) and Alpha-Step IQ Surface Profiler. Surface roughness of UB samples in between 0.11 to 0.21 $\mu \mathrm{m}$, UBdEL samples of 0.81 to $2.17 \mu \mathrm{m}$, UB+EL samples of 0.64 to $1.63 \mu \mathrm{m}$ and EL samples of 0.69 to $1.11 \mu \mathrm{m}$. The finest surface of each technique are located at UB $1.5 \mathrm{~h}$, UBdEL 45 minutes, UB $1.5 \mathrm{~h}+\mathrm{EL}$ 30 minutes and UB 30 minutes. That data is supported by coating thickness of coated FeCrAl substrate where UB samples in between $2-2.8 \mu \mathrm{m}$, UBdEL samples of 4.1 to $5 \mu \mathrm{m}$, UB+EL samples of 9.1 to $12 \mu \mathrm{m}$ and EL samples of 6.2 to $11.3 \mu \mathrm{m}$. To fulfil the requirement of industry that the product need to be fine surface and appropriate coating thickness, the appropriate techniques is shown by UB+EL technique especially for UB+EL 30 minutes.

\section{References}

[1] Heck R. M., Farrauto, R. J. \& Gulati, S. T. Catalytic Air Pollution Control Commercial Technology,3rded (John Wiley \& Sons, Inc., New Jersey), 2009: 114.

[2] Sebayang, D., Putrasari, Y., Sulaiman Hassan, \& Untoro, P. Preparation NiO Catalyst on FeCrAl Substrate Using Various Technique at Higher Oxidation Process, Electroplating, 2012; 1-25, ISBN 978-953-51-0471-1.

[3] Twigg, M. V. \& Webster, D. E. Metal and Coated Metal Catalysts. In: Structured Catalysts and Reactors, $2^{\text {nd }}$ ed, A. Cybulski. \& J. A. Moulijn, (Eds.), 71-108, Taylor \& Francis Group, ISBN 0-82472343-0, Boca Raton, FL. 2006; 109-146.

[4] Zhao, S., Zhang, J., Weng, D. \& Wu, X. A Method to Form Well-Adhered $\gamma-\mathrm{Al}_{2} \mathrm{O}_{3}$ Layers on FeCrAl Metallic Supports. Surface and Coating Technology, 2003; 167(1): 97-105.

[5] Chandni, R. \& Arthur, G. Growth of Hierarchically Structured High-Surface Area Alumina on FeCr alloy ${ }^{\circledR}$ Rods. Chinese Journal of Chemical Engineering, 2014; 22: 861-868.

[6] Ersson, A. G. \& Jaras, S. G. Catalytic Fuel Combustion in Honeycomb Monolith Reators. in Cybulski, A. and Moulijn, J.A. (Eds). Structured Catalysts and Reactors $2^{\text {nd }}$ ed. USA: Taylor and Francis Group, 2006: 233-237.

[7] Wu, X., Weng, D., Zhao, S. \& Chen, W. Influence of An Aluminized Intermediate Layer on The Adhesion of a Gamma- $\mathrm{AL}_{2} \mathrm{O}_{3}$ Washcoaton FeCrAl. Surface \& Coatings Technology, 2005; 190(2-3): 434- 439.

[8] Masakuni, O., \& Kenichi, A. Effect of La Modification on The Stability of Coating Alumina Layer on FeCrAl Alloy Substrate. Surface \& Coatings Technology, 2015; 271: 80-86.

[9] Gulati, S. T. Ceramic Catalyst Support for Gasoline Fuel. in Cybulski, A. \& Moulijn, J. A. (Eds). Structured Catalysts and Reactors $2^{\text {nd }}$ ed. USA: Taylor \& Francis Group, 2006.

[10] Putrasari, Y., Untoro, P., Hasan, S., Huda \& Sebayang, D. Modification of Surface Roughness and Area of FeCrAl Substrate for Catalytic Converter using Ultrasonic Treatment. Journal of Mechatronics, Electrical Power, and Vehicular Technology, 2010; 01. 
[11] Nicholls, J. R. \& Quadakkers, W. J. Materials Issues Relevant to the Development of Future Metal Foil Automotive CatalticConverters.In: Materials Aspects in Automotive Catalytic Converters, Hans Bode (Ed.), 31-48, Wiley-VCH Verlag GmbH, ISBN 3-527-30491-6, Weinheim, Germany, 2002.

[12] Pardiwala, J. M., Patel, F. \& Patel, S. Review Paper on Catalytic Converter for Automotive Exhaust Emission. International Conference On Current Trends In Technology, NUiCONE. 2011: 382-481.

[13] Sabatini, S., Kil, I., Dekar, J., Hamilton, T., Wuttke, J., Smith, M. A., Hoffman, M. A. \& Onori, S. A. New Semi-empirical Temperature Model for The Three Way Catalytic Converter. IFAC-Papers online, 2015; 48(15): 434-440.

[14] Hadi Pranoto, Dafit Feriyanto, Supaat Zakaria. Performance and Exhaust Gas Temperature Investigation of Ceramic, Metallic and FeCrAl Catalytic Converter In Gasoline Engine. Sinergi, 2019; 23(1):11-16. 